MBBS, MCPS, FCPS, MS Assistant Professor Obstetrics \&Gynaecology Department Isra University Hospital - Hyderabad.

Correspondence Address: Dr Ambreen Amna MBBS.MCPS.FCPS.MS

Assistant Professor

Obstetrics \& Gynaecology

Department

Isra University Hospital - Hyderabad ambreendoctor@gmail.com.

Article received on:

09/05/2014

Accepted for publication: 09/06/2014

Received after proof reading: $16 / 10 / 2014$

\title{
HYPERINSULINEMIA AND ITS ASSOCIATION WITH POLY CYSTIC OVARIAN SYNDROME
}

\begin{abstract}
Dr. Ambreen Amna
ABSTRACT... Objective: To determine the variable clinical presentation of Poly cystic ovarian Syndrome (PCOS) \& its association with Hyperinsulinaemia in young adolescent girls. Patients \& Methods: A descriptive study was conducted for one year from February 2009-2010 at Isra University Hospital Hyderabad (IUH). 136 adolescent girls who came in OPD with suspected features of polycystic ovarian syndrome were recruited. Biochemical test, ultrasound of pelvis and test to determine hyperinsulinemia were done .woman having preexisting ovarian pathology were excluded. All results were analyzed on statistical software SPSS version 16. Frequencies and percentages were calculated. Result: Insulin resistance significantly increased (43.4\%) in girls who have shown the features of PCOS. Weight gain observed in $69(50.7 \%$ - Obese) and $40(29.4 \%$ - very obese) of girls respectively. Different types of menstrual irregularities such as oligomenorrhea $50(36.8 \%)$, secondary amenorrhea $28(20.6 \%)$ primary amenorrhea 5 (3.7\%) were observed. 53(39.0\%) adolescent girls had normal cycle but evidence of PCO on ultrasound. Infertility was found in $32(23.5 \%)$ of participant followed by hirsutism\& acne in 59 (43.4\%) $45(33.1 \%)$ of woman respectively. Conclusions: There is significant association of PCOS with hyperinsulinemia. Hyperinsulinemia if persist can lead to metabolic syndrome with its serious sequelae. Steps should be taken for early recognition of PCOS in young woman.
\end{abstract}

Key words: $\quad$ PCOS, Obesity, Adolescent, Menstrual irregularities, Hyperinsulinemia.

Article Citation: Amna A. Hyperinsulinemia and its association with poly cystic ovarian syndrome. Professional Med J 2014;21(5):946-949.

\section{INTRODUCTION}

Polycystic ovary syndrome (PCOS)is the commonest endocrine disorder in women $^{1}$ with multiple etiologies and variable clinical presentation ${ }^{2,3,4}$. It can be manifested with high serum levels of androgens and insulin, hyperlipidemia, overweight, infertility, hirsutism, and acne ${ }^{5}$ it is also associated with a characteristic ovarian appearance on ultrasound scan. PCOS is stated that hyperandrogenaemia is primary, with insulin resistance a secondary consequence that mainly related to reduced insulin sensitivity in peripheral tissues, leading to hyperinsulinaemia, increase abdominal fat depots and modified skeletal muscle structure ${ }^{6,7,8}$. Prevalence of PCOS in general population is about $3-7 \%$.In Pakistan it rises up to $20.7 \%$ where it is associated with infertility in $6-8 \%{ }^{9}$. It is associated with obesity in $60 \%$ of women. It also increases the risk of diabetes and cardiovascular disease in $10 \%$ and $33 \%$ of women respectively. Adolescents with PCOS have a $30-60 \%$ prevalence of metabolic syndrome ${ }^{10}$. Polycystic ovary syndrome (PCOS) causes a wide range of problems that can have impact on health-related quality of life (HRQoL), emotional well-being and sexual satisfaction of women ${ }^{11}$. PCOS has a greater impact on women's psychological well-being when compared with chronic problems such as asthma, epilepsy, diabetes, backache, arthritis and coronary heart disease ${ }^{12}$. Some researchers also pointed out that adolescent with PCOS scored lower on subscales measuring general health perceptions, physical functioning, general behavior, and limitations in family activities because of illness.

\section{MATERIALS \& METHODS Operational Definitions Adolescents}

WHO defines "adolescents" as individuals in the 10-19 years age. Adolescence (lat adolescere, (to) grow) is a transitional stage of physical and mental human development that occurs between childhood and adulthood. 
Hirsutism: Hirsutism was defined by a modified Ferriman Gallwey score $>6$ and is characterized by excessive and increased hair growth on female humans in locations where the occurrence of terminal hair is normally absent or minimal.

Secondary Amenorrhea is defined as cessation of menstruation for more than six month in reproductive age group and was not due to pregnancy.

Oligomennorhea, Oligomennorhea means menses at interval of more than 35 days .

BMI. As recommended by $U$. S preventive services task force (USPSTF).

Body mass index (BMI) is a measure of body fat based on height and weight.

Normal built $19-25 \mathrm{~kg} / \mathrm{m} 2$

Overweight 26 - $30 \mathrm{~kg} / \mathrm{m} 2$

Obese 31 - $40 \mathrm{~kg} / \mathrm{m} 2$

Very obese $>40 \mathrm{~kg} / \mathrm{m} 2$

Infertility was described as inability of a couple to conceive within one year.

Poly cystic ovarian morphology on ultrasound. Polycystic ovaries were defined as enlarged ovaries with 8-10 follicles of 2-8 $\mathrm{mm}$ in diameter arranged on the periphery of ovaries and increased stromal thickness.

\section{DATA COLLECTION PROCEDURE}

All the adolescent girls who has came with oligomenorrhea, Amenorrhea (Primary\& Secondary) Hirsutism, obesity were further explored by asking specific questions like menarche, cycle regularity, duration, amount of bleeding, Acne, Hirsutism, weight gain, inability to conceive. Young girls with normal menstrual cycle with evidence of poly cystic ovaries on ultrasound. Family history of PCOS \& Diabetes in first degree relatives were included, however woman with preexisting pelvic pathology endocrine disorders were excluded. After that thorough examination including height in meter \& weight in Kilogram were done. Women were advised for biochemical tests including $\mathrm{FSH}$ and $\mathrm{LH}$ ratio and Ultrasound pelvis. Woman who were fulfilling the criteria was advised for 12 hour fast and fasting serum insulin level were checked by draining 2 cc of venous blood, To standardized the test it was carried out from single laboratory. Hyperinsulinemia was considered when level is more than $17 \mathrm{U}$ mico $\mu / \mathrm{ml}$.

\section{RESULT}

Table I depicts the demographic features of study participants' .The mean + SD age is found to be $18.21+22$ years; whereas the median, mode and range were 18 . $20 \& 15$ years respectively. While elaborating the effects of menstrual irregularities having features of PCOS \& hyperinsulinemia $50(36.8 \%)$ adolescent girls gave the history of oligomenorrhea, while 53 ( 39.0\% ) had normal cycle but evidence of poly cystic ovaries (PCO) on ultrasound. 28 (20.6\%) had Secondary Amenorrhea and 5 (3.7\%) were primary Amenorrhea. Infertility was found in $32(23.5 \%)$ of girls. Weight gain was the commonest presenting complain found in 69 adult girls after calculating their BMI. 29 ( $21.3 \%$ ) girls were found to be obese and 40 ( $29.4 \%$ ) were very obese , while 67 (49.3\%) had normal BMI .81 (59.6\%) had positive family history of diabetes in first degree relative shown in Table I.

Sign of Hyperandrogenism including Hirsutism\& acne were seen in 59 (43.4\%) and 45 (33.1\%) of girls respectively however reverse LH / FSH ratio were found in $39 \%$ of woman shown in table II. Fasting serum insulin level were normal in 77 (56.6\%) while 59 (43.4\%) girls had level above17 micro $\mathrm{U} / \mathrm{ml}$ indicating hyperinsulinemia shown Table-III.

\section{DISCUSSION}

Insulin resistance defined as decrease biological response to a given amount of insulin ${ }^{12}$. Now a day's most attention is focused on the role of insulin resistance and hyperinsulinemia in the development of the PCOS and it is more pronounced in adolescent. Present studies showed adolescent ages between 11-20 years. Presences of menstrual irregularities are must for the diagnosis of PCOS. Menstrual irregularities 


\begin{tabular}{|c|c|c|}
\hline Variables & $\begin{array}{c}\text { No. of } \\
\text { Subjects }\end{array}$ & \%age \\
\hline $\begin{array}{c}\text { Normal cycle } \\
\text { (evidence of PCO on } \\
\text { ultrasound) }\end{array}$ & 53 & $(39.0 \%)$ \\
\hline Oligomennorrhea & 50 & $(36.8 \%)$ \\
\hline Secondary Amenorrhea & 28 & $(20.6 \%)$ \\
\hline Primary Amenorrhea & 05 & $(3.7 \%)$ \\
\hline Anovulation / Infertility & 32 & $(23.5 \%)$ \\
\hline Woman having normal BMI & 67 & $(49.3 \%)$ \\
\hline Obese & 40 & $(29.30 \%)$ \\
\hline $\begin{array}{c}\text { Positive family history of } \\
\text { diabetes in first degree } \\
\text { relatives }\end{array}$ & 81 & $(59.6 \%)$ \\
\hline
\end{tabular}

Table-I. Showing the menstrual irregularities in young girls with PCOS:

\begin{tabular}{|c|c|c|}
\hline Variables & $\begin{array}{c}\text { Number } \\
(\mathbf{n = )}\end{array}$ & \%age \\
\hline Sign of hyperandrogenism & 59 & $43.4 \%$ \\
\hline Acne & 45 & $33.1 \%$ \\
\hline Reverse FSH and LH & 54 & $39 \%$ \\
\hline
\end{tabular}

Table-Il. Showing the features of androgenization in adolescent girls with PCOS: $(n=136)$.

\begin{tabular}{|c|c|c|}
\hline Insulin Level & $\begin{array}{c}\text { Number of } \\
\text { patients }\end{array}$ & $\begin{array}{c}\text { Percentages } \\
\text { (\%) }\end{array}$ \\
\hline 3-10 micro U/ml & 57 & $41.9 \%$ \\
\hline$>10-14 \mathrm{micro} U / \mathrm{ml}$ & 13 & $9.5 \%$ \\
\hline$>14-16 \mathrm{micro} \mathrm{U} / \mathrm{ml}$ & 09 & $6.61 \%$ \\
\hline$>17 \mathrm{micro} U / \mathrm{ml}$ & 59 & $43.4 \%$ \\
\hline
\end{tabular}

Table-III. Indicating Serum Insulin Level of adolescent girls diagnosed as having Polycystic ovarian syndrome $(n=136)$

have hallmarks association with PCOS. In study conducted by Stein and Leventhal amenorrhea was the presenting complain ${ }^{1}$. However in other study of 1741 with PCOS $30 \%$ of woman had regular menses and $66 \%$ had amenorrhea and Oligomenorrhea respectively ${ }^{2}$. Present study showed normal cycle with features of PCOS in $39 \%$ oligomenorrhea in $36 \%$ and association of primary \& secondary amenorrhea in $20 \%$ and $3 \%$ of woman respectively. Similarly Rasool et al also find an association with hirsutism \&oligomenorrhea with polycystic ovaries in 57.7\% of woman ${ }^{3}$. Obesity, particularly the abdominal phenotype, may be partly responsible for insulin resistance in women with $\mathrm{PCOS}^{13}$. Therefore, obesity-related hyperinsulinaemia may play a key role in favoring hyperandrogenism in these women ${ }^{14}$. 19 Present Study showed that 69 girls gave history of weight gain after calculating their BMI. 67 (49.3\%) had normal BMI while 29(21.31\% ) were found to be obese. While comparing the result of obesity related to PCOS present study found similar association with that of Tan's study $^{14}$. The incidence of infertility with PCO in this study is $24 \%$. Which is just similar to another study by Irshad (25\%) \& Baqai (49.9\%) respectively ${ }^{15}$. Acne and Hirsutism are found in $45 \%$ and $43.4 \%$ of girls respectively. According to study by Adil $\mathrm{F}^{16}$, Hirsutism and Acne were also seen in $62.49 \%$ of woman respectively. According to Zhang et al there is a strong correlation of women with hyperinsulinemia and first degree relatives with diabetes ${ }^{17}$. Similarly in present study 81 (59.6\%) with PCOS had a positive family history of diabetes. On Trans abdominal Ultrasound evidence of PCOS was found in $22(16.18 \%)$ of adolescent girls. Similarly Kashif ${ }^{18}$ et al reported that $93 \%$ of PCOS were diagnosed on ultrasound however the sample size is more as compare to present study and most of the ultrasound were performed by transvaginal route. Hyperinsulinaemia can be a primarily pathology in young PCO adolescent girls responsible for metabolic syndrome. In present study $43.4 \%$ of adolescent girls had hyperinsulinemia which indicate significant insulin resistance .Every adolescent girls who fulfill the criteria of PCOS must undergo checking for fasting serum insulin levels. This strategy should be familiar to every young doctors and family physician so that early detection and intervention can be made soon.

\section{ACKNOWLEDGMENT}

Author is very indebted to women who give willingness for study's enrolment as well as Laboratory workers who gave reports without delay .

\section{CONCLUSIONS}

Hyperinsulinemia is an emerging health problem with significant association with metabolic syndrome including PCOS. 
General Practitioners and family physician should be aware to think about this common disorder in adolescent age group for early diagnosis and further prevention of complications of metabolic syndrome associated with PCOS.

\section{Copyright@ 09 June 2014.}

\section{REFERENCE}

1. Franks $S$. Polycystic ovary syndrome in adolescents. Int J Obes Lond 2008; 32:1035-41.

2. Brien RF. Emans SJ. Polycystic ovary syndrome in Adolescents. $J$ pediatric Adolesc Gynaecol.2008;21:119-128.

3. Ahmed Y, Akhtar A, Reshi FQ, Anjum Q, Hatl HA. Poly cystic Ovarian Syndrome: a new perspective. J Pak Med Assoc 2003; 53:72-7.

4. Mason, Helen D., Nafi Dilaver, and Suman Rice. "Ovarian Dysfunction in Polycystic Ovary Syndrome." Polycystic Ovary Syndrome. Springer New York, 2014. 53-70.

5. Lina W, Jie $Q$, Meizhi L. The clinical characteristics of poly cystic ovary syndrome in adolescence. Jfertnstert2006;86:461.

6. Creatsas G, Deligeoroglou E.Polycystic ovarian syndrome in adolescent's. curr opin Obstet Gynecol 2007; 19:420-426.

7. Zawdaki JK, Dunaif A. Diagnostic criteria for poly cystic ovary Syndrome: Towards a rational approach. In: Dunaif A, Given JR, Heseltine F, Merriam GR eds. Poly cystic ovary syndrome. Boston: Black well. 1992; 377-84.

8. The Rotterdam ESHRE/ASRM - Sponsored PCOS consensus Work shop group. Revised 2003 consensus on diagnostic criteria and Long term health risks related to polycystic ovarian syndrome. Hum Re Prod 2004; 19:41-7.
9. Palomba S, Falbo A, RussoT, Zullo f. Ovulation Induction in Anovulatory Patients with polycystic ovary syndrome .current drug therapy 2006; 1: 23-29.

10. Lindenberg, Svend. "New approach in patients with polycystic ovaries, lessons for everyone." Fertility and sterility 99.5 (2013): 1170-1172.

11. Barber, Thomas M., and Stephen Franks. "Divergences in insulin resistance between the different phenotypes of the polycystic ovary syndrome." Expert Review of Endocrinology \& Metabolism 8.5 (2013): 427-429.

12. Leonard, Phoebe H., Jani R. Jensen, and Gaurang S. Daftary. "Surgical Management of Polycystic Ovary Syndrome: A Contemporary Viewpoint on Place of Ovarian Surgery in PCOS Management." Polycystic Ovary Syndrome. Springer New York, 2014. 289-299.

13. Arslanian S, Witchel SF. Polycystic ovary syndrome in adolescents: is there is epidemic?. current opinion in Endocrinology \& Diabetes 2002; 9:32-42.

14. Tan et al. Large effects on body mass index and insulin resistance of fat mass and obesity associated gene (FTO) variants in patients with polycystic ovary syndrome (PCOS) BMC Medical Genetics 2010, 11:12.

15. Baqai Z, Khanam M, Parveen S. Prevalence of PCOS in infertile patients-Medical channel . Vol. 16, No. 3 JULY - SEPTEMBER 2010.

16. Adil F, Ansar H, Munir A. Poly cystic ovarian syndrome and hyper insulinaemis. JLUMHS 2005 ; 4: 89 - 93 .

17. Zhang HY, ZhuFF, Xiong J, Shix B, Fu SX. Characteristics of different phenotypes of poly cystic syndrome based on the Rotterdam criteria in a large scale Chinese population. BJOG 2009; 116 : 1633 - 1639.

18. Kashif F, Tabassum S, Bhatti A, Laghari I, Baloch R . Clinical diagnosis of poly cystic ovarian syndrome and response to metformin theraphy in respective of menstrual irregularities and conception rate. Med channel 2010; 16:149-151. 